\title{
Early pain detection and management after esophageal metal stent placement in incurable cancer patients: A prospective observational cohort study
}

Authors

Institution
Agnes N. Reijm, Paul Didden, Marco J. Bruno, Manon C.W. Spaander

Department of Gastroenterology and Hepatology, Erasmus Medical Center, Rotterdam, the Netherlands submitted

18. November 2015 accepted after revision 13. June 2016

\section{Bibliography}

DOI http://dx.doi.org/

10.1055/s-0042-111202

Published online: 9.8.2016

Endoscopy International Open

2016; 04: E890-E894

(c) Georg Thieme Verlag KG

Stuttgart · New York

E-ISSN 2196-9736

\section{Corresponding author}

\section{Manon C. W. Spaander}

Department of

Gastroenterology and

Hepatology (room Hs-312)

Erasmus University

Medical Centre

's Gravendijkwal 230,

3015 CE Rotterdam

The Netherlands

Phone: +31 (0) 107035643

Fax: +31 (0) 107035172

v.spaander@erasmusmc.nl
Background and study aims: Studies of esophageal self-expandable metal stents (SEMS) mainly focus on efficacy and recurrent dysphagia. Retrosternal pain has been described in up to $14 \%$ of these patients, however, prospective daily pain assessment has not yet been performed. We conducted a prospective study to evaluate the occurrence and management of pain after esophageal SEMS deployment.

Patients and methods: A total of 65 patients who underwent SEMS placement for incurable malignant esophageal stenosis were included. Patients used a diary to record intensity of pain twice daily for 2 weeks, according to the Numeric Rating Scale (NRS). A pain score $\geq 4$ was used to determine whether patients experienced significant pain. If pain occurred, acetaminophen was used and, in cases of ongoing pain, an opiate was pre-

\section{Introduction}

$\nabla$

Esophageal cancer is the eighth most common cancer worldwide [1], with more than 400,000 deaths per year [2]. Despite recent advances in the treatment of esophageal cancer, $50 \%$ of patients still have incurable disease at the time of presentation because of metastasis or locally advanced disease [3]. Dysphagia is a devastating symptom of incurable obstructive esophageal cancer with a major impact on patient's quality of life. Options for treating dysphagia includes self-expandable metal stent (SEMS) placement, external beam radiation, and brachytherapy [46].

Although brachytherapy has shown to provide better long-term relief of dysphagia, SEMS placement leads to more rapid improvement [7]. Furthermore, endoscopic stent placement is also an effective palliative measure for management of malignant esophageal fistula [5]. The aim of stenting is to restore luminal patency and thereby maintain nutritional intake and improve quality scribed. Dose, duration, and kind of analgesic were noted.

Results: The rate of significant pain increased from $0 \%$ at baseline to $60 \%$ on Day $1(P<0.001)$, followed by $37 \%$ and $25 \%$ on Days 7 and 14 , respectively. The rate of analgesics use increased from $20 \%$ at baseline to $78 \%$ on Day $1(P<0.001)$, followed by $72 \%$ and $62 \%$ on Days 7 and 14 , respectively. The use of opiates increased from $14 \%$ at baseline to $42 \%$ on Day $1(P<0.001)$. No variables associated with SEMS related pain were found.

Conclusions: Two-thirds of patients experience significant pain after esophageal SEMS insertion and analgesics, including opiates, are frequently required. Patients need to be informed and preventive prescription of analgesia should be considered in order to improve quality of life.

of life [5]. SEMS are the most commonly used stents and different types of stents are available. Palliative stent insertion has been shown to result in significant improvement in all scales of quality of life, except for pain [8]. Pain is one of the most common symptoms in cancer patients. Its intensity increases as the disease advances, with a reported prevalence of $64 \%$ in patients with metastatic or advanced stage disease $[9,10]$.

A great variety of measures are available to assess cancer pain. One of the most commonly used pain rating scale is the Numerical Rating Scale (NRS). The NRS is a 11 point scale where the end points are the extremes of no pain and worst pain. The NRS is well accepted by patients $[11,12]$. The "cut-off" point for experiencing significant pain is when a pain score of 4 or higher is noted. It has been shown that at that level, pain has a major impact on daily functioning $[13,14]$. Undertreatment of pain is associated with significant functional impairments, poor sleep, increased depression and anxiety, and impaired quality of life [15]. In studies reporting on the outcome of esophageal 
stenting, but in which post-procedural pain management was not the primary focus of the study, $3.6 \%$ of patients develop severe retrosternal pain and $14.1 \%$ develop mild retrosternal pain after esophageal SEMS insertion [16-27]. However, in our experience, in daily practice, the rate is much higher. For that reason, we conducted a prospective study to systematically evaluate the occurrence and management of pain in a large cohort of consecutive patients after esophageal SEMS deployment.

\section{Patients and methods}

\section{Patients}

Between March 2011 and December 2013, consecutive patients who were treated with an esophageal SEMS for a malignant esophageal or cardiac stricture or concomitant fistula were enrolled in this study. Patients were included if they suffered from dysphagia, at least grade 2 (ability to eat semisolids only) or symptoms compatible with esophageal fistula. Patients with extrinsic malignant compressions or after esophageal resection with gastric tube reconstruction were also eligible for inclusion. Exclusion criteria were inability to fill out a pain diary or inability to undergo an upper endoscopy.

\section{Endoscopic stent placement}

Esophageal stent placement was performed under conscious sedation using midazolam and/or fentanyl. The lesion was inspected with a standard or pediatric video endoscope to determine location and length of the stenosis and/or malignant fistula. The length of the SEMS was chosen based on the stricture length plus a minimum of $2 \mathrm{~cm}$ at each side. SEMSs from various manufacturers were allowed and selection was based on availability and physician discretion. The SEMS was advanced over a guidewire until it passed the distal end of the stenosis, and then it was deployed under endoscopic guidance and in some cases also under fluoroscopic guidance. After the procedure, patients stayed in the endoscopy department for 2 to 3 hours for observation. Thereafter, they returned home or to the ward.

\section{Pain assessment}

All patients completed a pain diary at baseline and every day for 2 weeks after esophageal SEMS placement. They recorded the severity of pain twice daily using the numerical rating scale (NRS). This scale consists of a series of numbers from 0 to 10 , with zero representing no pain and 10 representing an extreme level of the worst imaginable pain. The daily highest pain score was noted and used for analysis. Patients were followed up by phone 7 days and 14 days after SEMS placement to collect the daily NRS scores. A pain score $\geq 4$ was used to determine whether patients experienced significant pain. Pain scores were also classified as mild, moderate, or severe, representing a pain intensity of 1 to 3 , 4 to 6 , and 7 to 10 , respectively.

\section{Analgesic regimen}

We used the 3-step ladder for cancer pain relief in adults according to the World Health Organization (WHO). If pain occurs, acetaminophen $(1000 \mathrm{mg}$ ) was started 3 to 4 times daily. The second step of prescribing mild opioids was routinely skipped. If acetaminophen did not provide adequate pain relief (NRS $\geq 4$ ), strong opioids were started, either transdermal fentanyl (Fentanyl, Bipharma, Hameln, Germany) or long-acting oxycontin (Oxycodon, Mudipharma Pharmaceuticals B.V., Hoevelaken, The Nether- lands). In case of breakthrough pain, patients received short-acting oxynorm (Oxycodon, Mudipharma Pharmaceuticals B.V., Hoevelaken, The Netherlands) given a maximum of 6 times a day. Dosage was modified according to the reported NRS score collected on Day 7 and 14 after SEMS placement. Furthermore, patients were instructed to call in case of significant pain at any moment, and dosage was re-evaluated accordingly. Dosage of strong opioids was increased with the intent of achieving adequate pain relief $(\mathrm{NRS}<4)$. The type and dosage of pain medication were recorded at baseline and after 1 and 2 weeks. In order to compare dosages of different opioids, daily dosages of fentanyl and oxycontin were converted to an equivalent dosage of morphine.

\section{Statistical analysis}

Patient demographics and clinical characteristics were presented using descriptive statistics. Overall survival after stent placement was calculated using the Kaplan-Meier method. Pain scores and proportion of patients with pain score $\geq 4$ were compared at different time points using the paired T-test and McNemar's test, respectively. Also proportion of patients using analgesics between different time points were analyzed using the McNemar's test's. Pain score $\geq 4$ over time at different time points after day 0 was analyzed using logistic regression with repeated measurement to account for correlation between measurements in the same patient (SAS 9.4, PROC GENMOD). To assess the effect of covariates on pain over time, we considered time as a linear factor and in time we assessed the following covariates: gender, age, degree of dysphagia, histology, tumor location, previous treatment with chemotherapy or radiotherapy and stent type. Factors with a $P<0.20$ in the univariable analysis were entered into a multivariable stepwise regression model. A $P$ value $<0.05$ was considered statistically significant. All calculations were done using the SPSS 21 statistical software package (SPSS, Chicago, Illinois, United States) and SAS 9.4.

\section{Results \\ $\nabla$}

Patient and stent characteristics

Sixty-five patients were treated with a SEMS for a malignant stricture of the esophagus $(\mathrm{N}=58)$ or gastric tube $(\mathrm{N}=7)$, including 6 patients with a concomitant fistula. Table 1 shows the clinical characteristics of these patients. Endoscopic SEMS insertion was technically successful in all patients. Five types of stents were used: partially covered Ultraflex stents (Boston Scientific, Natick, Mass, United States), partially covered Evolution stents (Cook Medical, Bloomington, IN, United States), fully covered Hanaro stents (M.I. Tech, Korea) and partially as well as fully covered Wallflex stents (Boston Scientific, Natick, Mass, United States). Median length was $10 \mathrm{~cm}$ and median diameter was $18 \mathrm{~mm}$. None of the patients underwent dilation to facilitate SEMS placement. Median survival after stent placement was 10 weeks (95\% CI: 5.6-14.3, Kaplan-Meier survival curve, $\bullet$ Fig. 1).

\section{Pain}

A pain diary was filled out as requested by all 65 patients. Two patients died 1 week after SEMS insertion and therefore, pain scores for the second week were not available. At baseline, none of the patients experienced significant pain (i.e. pain score $\geq 4$ ) with a median pain score of 0 . On the first day after SEMS insertion, 39 patients $(60 \%)$ reported significant pain $(P<0.001)$. On Days 7 and 
Table 1 Baseline characteristics of 65 patients.

\begin{tabular}{|c|c|}
\hline Characteristics & No \\
\hline Sex (male/female) & $50 / 15$ \\
\hline Median age, y (range) & $66(39-89)$ \\
\hline \multicolumn{2}{|l|}{ Histology } \\
\hline Adenocarcinoma & $37(57 \%)$ \\
\hline Squamous cell carcinoma & $26(40 \%)$ \\
\hline Other & $2(3 \%)$ \\
\hline \multicolumn{2}{|l|}{ Location } \\
\hline Proximal esophagus & $4(6 \%)$ \\
\hline Mid esophagus & $20(31 \%)$ \\
\hline Distal esophagus & $34(52 \%)$ \\
\hline Gastric tube after esophageal resection & $7(11 \%)$ \\
\hline \multicolumn{2}{|l|}{ Indication SEMS insertion } \\
\hline Stenosis & $59(91 \%)$ \\
\hline Stenosis with fistula & $6(9 \%)$ \\
\hline \multicolumn{2}{|l|}{ Dysphagia score } \\
\hline Grade 2 (able to eat semi-solid foods) & $5(9 \%)$ \\
\hline Grade 3 (able to swallow liquids only) & $41(60 \%)$ \\
\hline Grade 4 (unable to swallow anything) & $19(31 \%)$ \\
\hline \multicolumn{2}{|l|}{ Type of SEMS } \\
\hline Boston Ultraflex $\left(\mathrm{pc}^{1}\right)$ (small body) & $18(28 \%)$ \\
\hline Cook Evolution ( $\left.\mathrm{pc}^{1}\right)$ (wide body) & $14(21 \%)$ \\
\hline M.I. Tech Hanaro stent $\left(\mathrm{fc}^{2}\right)$ (small body) & $9(14 \%)$ \\
\hline Boston Wallflex ( $\left.\mathrm{fc}^{2}\right)$ (small body) & $10(15 \%)$ \\
\hline Boston Wallflex $\left(\mathrm{pc}^{1}\right)$ (small body) & $14(22 \%)$ \\
\hline Pretreatment & $46(71 \%)$ \\
\hline Chemotherapy & $16(25 \%)$ \\
\hline Radiotherapy & $3(4 \%)$ \\
\hline Chemo/radiotherapy & $23(34 \%)$ \\
\hline Brachytherapy & $5(8 \%)$ \\
\hline
\end{tabular}

14 , significant pain was observed in 24 (37\%) and 16 patients (25 $\%$ ), respectively ( $\bullet$ Fig. 2 ). The highest pain score was noted on Day 1 , with a median pain score of 5 (range $0-10$ ). Median pain scores were 3 (range 0 - 8) on Day 7 and 1 (range 0 - 8) on Day 14. Univariable logistic regression analysis is shown in $\bullet$ Table 2. No significant differences were found in occurrence of significant pain after SEMS placement over time.

\section{Analgesics}

At baseline, 13 patients (20\%) were using analgesics, either acetaminophen and/or opiates. On the first day after SEMS insertion, any kind of analgesic use significantly increased to $78 \%$ $(P<0.001)$ and declined to $72 \%$ and $62 \%$ on Days 7 and 14 , respectively.

Fourteen patients (22\%) did not require any analgesic drug during 2 weeks of follow up. In 23 patients (35\%), adequate pain relief was achieved with use of only acetaminophen. Irrespective of use of opioids, the number of patients using acetaminophen, significantly increased after stent placement, from $13.8 \%$ at baseline to $73.8 \%$ on Day $1(P<0.001)$ and decreased during follow-up from $67.7 \%$ on Day 7 to $58.5 \%$ on Day 14 .

Because of insufficient pain relief with acetaminophen, 18 patients (28\%) started opiates on the first day after stent placement, with a mean daily morphine dose of $43.2 \mathrm{mg}$. During follow up, dosage decreased to a mean dosage of $39.3 \mathrm{mg}$ on Day 7 and $32.0 \mathrm{mg}$ on Day 14 . Only 1 patient started opiates 1 week after stenting, using morphine $40 \mathrm{mg}$ daily, without dosage modifica-

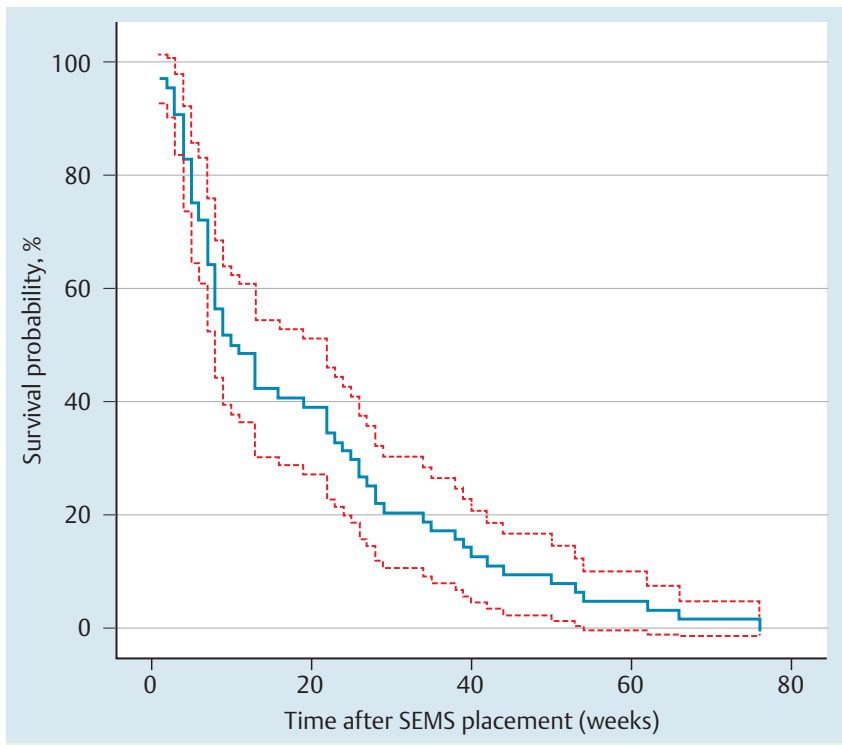

Fig. 1 Kaplan-Meier curve (bold line) and 95\% pointwise confidence limits (dashed lines) for the survival function after SEMS placement.

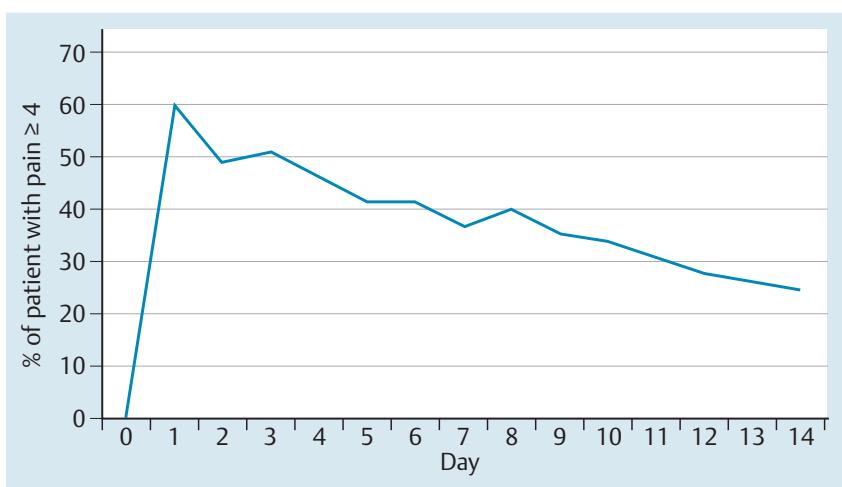

Fig.2 Percentage of patients experiencing significant pain during the first 14 days after esophageal SEMS insertion (pain score $\geq 4$ ).

Table 2 Univariable analysis on development of a pain score $\geq 4$ after SEMS placement. ${ }^{1}$

\begin{tabular}{|c|c|c|c|}
\hline \multirow[t]{2}{*}{ Covariate } & & \multicolumn{2}{|l|}{$\begin{array}{l}\text { Univariable } \\
\text { analysis }\end{array}$} \\
\hline & & OR (95\% Cl) & $P$ value \\
\hline Gender & Female vs. male & $0.97(0.87-1.08)$ & 0.53 \\
\hline Histology & $\begin{array}{l}\text { Squamous cell carcino- } \\
\text { ma vs. adenocarcinoma }\end{array}$ & $0.93(0.79-1.09)$ & 0.39 \\
\hline $\begin{array}{l}\text { Prior } \\
\text { radiotherapy }\end{array}$ & No vs. yes & $1.09(0.99-1.19)$ & 0.06 \\
\hline $\begin{array}{l}\text { Prior } \\
\text { chemotherapy }\end{array}$ & No vs. yes & $0.98(0.89-1.07)$ & 0.65 \\
\hline Dysphagia & Grade: 4 vs. $2-3$ & $1.06(0.96-1.16)$ & 0.24 \\
\hline $\begin{array}{l}\text { Tumor } \\
\text { location }\end{array}$ & Distal vs. proximal/mid & $0.97(0.88-1.07)$ & 0.52 \\
\hline \multirow[t]{2}{*}{ Type of stent } & Hanaro vs. Ultraflex & $0.91(0.79-1.05)$ & 0.21 \\
\hline & Wallflex vs. Ultraflex & $0.97(0.87-1.08)$ & 0.60 \\
\hline
\end{tabular}

1 Odds ratios (OR) represents the relative difference in pain decrease per day between groups. 
tion during the second week. Nine patients (14\%) were already using opiates at baseline, with a mean daily morphine dosage of $74.7 \mathrm{mg}$. In these 9 patients, dosage increased to $98.7 \mathrm{mg}$, $132.0 \mathrm{mg}$ and $145.4 \mathrm{mg}$ on Days 1, 7 and 14, respectively. Overall, the percentage of patients using any form of opiate significantly increased after stent placement, from $13.8 \%$ at baseline to $41.5 \%$ on Day $1(P<0.001)$. Proportions of patients using acetaminophen, opiates and a combination are shown in $\bullet$ Fig. 3.

\section{Adverse events}

During the 2-week study period, a total of 12 adverse events (AEs) in 11 patients were recorded. Distal migration of the stent was observed in 6 patients, with a median of 3.5 days after stent insertion. All were managed endoscopically. In 2 patients the stent was removed, after which a new metal stent was deployed. In the remaining 4 cases the stent was repositioned using a grasping forceps. Food impaction inside the stent occurred in 1 patient 3 days after stent placement and was treated with endoscopic cleaning. Pulmonary complications were encountered in 3 patients, including aspiration pneumonia ( $\mathrm{n}=2$, after a median of 3 days) and symptomatic tracheal compression directly after esophageal stent insertion. The latter was managed by placing a tracheal stent. One patient developed mediastinal air and para-esophageal fluid collections on computed tomography scan after 8 days, suspected of an esophageal perforation. This patient was managed conservatively with antibiotics and survived the 2-week follow-up. One patient died due to a probable upper gastrointestinal bleeding and another due to progressive disease.

\section{Discussion}

$\nabla$

Metal stenting is one of the most widely used palliative treatment modalities for malignant dysphagia and fistula, mainly because of a favorable and rapid clinical response. However, stentrelated AEs are not infrequently encountered. In this prospective study, we have shown that $60 \%$ of patients develop significant pain immediately after SEMS insertion. Although post-procedural pain gradually diminishes over time, $25 \%$ of patients still report significant pain after 2 weeks, despite analgesic therapy.

A key domain of palliative care is the focus on optimizing comfort by reducing symptoms. Pain is one of the most essential symptoms because of its huge impact on daily functioning and quality of life $[13,14]$. Therefore, it is of utmost importance that pain be recognized early and adequately treated [28].

Considering our findings, we believe that pain after SEMS placement has been largely underestimated in previous reports and perhaps also in clinical practice. In literature, incidences of up to $14 \%$ have been described, however post-procedural pain management was not the primary focus in these studies [16-27]. In fact, this is the first study evaluating pain experience in a prospective fashion using daily registration. An important finding of our study is the high incidence and intensity of pain on Day 1 after stent placement, accompanied by a high consumption of analgesics. This is probably related to the instant expansion of the SEMS after deployment. Strong radial and axial forces induce stretching of the malignant process, but also cause pressure that damages the surrounding esophageal wall. The esophagus eventually seems to conform to the fully expanded SEMS. This might explain why severity of pain and need for analgesic therapy gradually decrease over time.

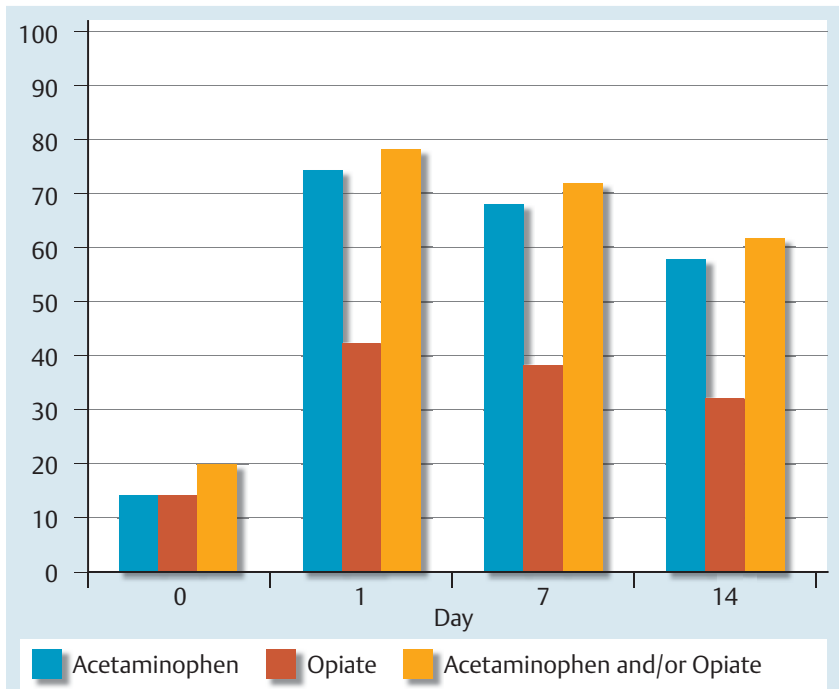

Fig. 3 Percentage of patients using analgesics before and during first 2 weeks after SEMS placement.

One of the aims of our study was to identify patient- or stentrelated factors that might predict development of pain after SEMS placement. A previous in vitro study has shown variation in radial and axial force patterns among esophageal SEMS [29]. It is assumed that SEMS with a higher axial force cause more retrosternal pain due to high pressure and damage to the esophageal wall. This assumption was supported by 2 reports on the Wallflex stent, a SEMS with a high axial force, demonstrating a relatively high incidence of retrosternal pain and pressure ulceration $[17,30]$. Considering radial forces, it seems that 2 different pressure profiles can be distinguished [29]. The first group (e.g. Evolution and Wallflex) is associated with a relatively low initial radial force with gradual decline during expansion, while the second group (e.g. Ultraflex and Hanaro) demonstrates an initial high radial force followed by a rapid decline during expansion. The features of the second group could potentially induce more pain due to immediate forceful dilation of the stricture. However, in our current study, we were not able to find a relation between type of stent and pain experience, especially not when stents were grouped according to their pressure profile. This might be related to the limited number of each type of stent that was used, and probably also influenced by other stent- and patientrelated factors. However, several factors were tested using regression analysis, but none appeared to be predictive of the occurrence and length of significant post-procedural pain. In particular, we didn't find any effect of previous treatment with chemotherapy and/or radiation on pain. These results are in line with other studies, showing similar incidences of chest pain in patients with and without prior treatment. However, these findings should still be interpreted with caution, considering the limited number of patients and potential under-registration of post-procedural pain in other studies.

Approximately $40 \%$ of the patients were in need of opioids and in most of them, opioid therapy could not be discontinued. We did observe a decline in daily dosage in patients who started opioids directly after SEMS placement. These issues are extremely relevant for patients as they are in need of optimal palliative care. For that, reason physicians should discuss the possible occurrence of post-procedural pain with patients prior to SEMS placement. In our opinion, preemptive opioid therapy is not indicated, 
but opioids should be started if sufficient relief cannot be achieved with acetaminophen. A specialized oncology nurse can be recommended to closely monitor and guide these patients, especially shortly after SEMS placement.

There are some limitations of our study that should be acknowledged. Scoring pain intensity using the NRS is subjective and comparing one patient's pain with another's should be done with caution. Pain perception is based on (mal)adaptive behavioral patterns, psychological and social factors, which were not addressed in our study. On the other hand, objective diagnostic tests assessing pain intensity are not available and besides individual analgesic need, the NRS scale is, in our opinion, the most appropriate rating tool at this time.

\section{Conclusions}

$\nabla$

In conclusion, SEMS for malignant esophageal disease results in moderate to severe pain in $60 \%$ of patients immediately after stent placement and approximately $75 \%$ of patients require some form of analgesic therapy. Patients need to be informed about this very common side effect and proactive management is needed in order to prevent post-procedural pain.

Competing interests: Prof. Dr. M.J. Bruno reports grant and personal fees from Boston Scientific, grants and personal fees from Cook Medical, and personal fees from SOCAR outside the submitted work.

\section{References}

1 Ferlay J, Shin HR, Bray F et al. Estimates of worldwide burden of cancer in 2008: GLOBOCAN 2008. Int J Cancer 2010; 127: 2893-2917

2 Parkin DM, Bray FI, Devesa SS. Cancer burden in the year 2000. The global picture. Eur J Cancer 2001; 37: 084-66

3 Stein HJ, Siewert JR. Improved prognosis of resected esophageal cancer. World J Surg 2004; 28: 520-525

4 Homs MY, Eijkenboom WM, Coen VL et al. High dose rate brachytherapy for the palliation of malignant dysphagia. Radiother Oncol 2003; 66: $327-332$

5 Didden P, Spaander MC, Bruno MJ et al. Esophageal stents in malignant and benign disorders. Curr Gastroenterol Rep 2013; 15: 319

6 Murray LJ, Din OS, Kumar VS et al. Palliative radiotherapy in patients with esophageal carcinoma: A retrospective review. Pract Radiat Oncol 2012; 2: 257-264

7 Homs MY, Steyerberg EW, Eijkenboom WM et al. Single-dose brachytherapy versus metal stent placement for the palliation of dysphagia from oesophageal cancer: multicentre randomised trial. Lancet 2004; 364: $1497-1504$

8 Madhusudhan C, Saluja SS, Pal S et al. Palliative stenting for relief of dysphagia in patients with inoperable esophageal cancer: impact on quality of life. Dis Esophagus 2009; 22: 331 - 336

9 Anton A, Montalar J, Carulla J et al. Pain in clinical oncology: patient satisfaction with management of cancer pain. Eur J Pain 2012; 16 : $381-389$

10 van den Beuken-van Everdingen MH, de Rijke JM, Kessels AG et al. Prevalence of pain in patients with cancer: a systematic review of the past 40 years. Ann Oncol 2007; 18: 1437-1449
11 Jensen MP. The validity and reliability of pain measures in adults with cancer. J Pain 2003; 4: 2-21

12 Williamson A, Hoggart B. Pain: a review of three commonly used pain rating scales. J Clin Nurs 2005; 14: 798-804

13 Paul SM, Zelman DC, Smith M et al. Categorizing the severity of cancer pain: further exploration of the establishment of cutpoints. Pain 2005; 113: $37-44$

14 Serlin RC, Mendoza TR, Nakamura $Y$ et al. When is cancer pain mild, moderate or severe? Grading pain severity by its interference with function. Pain 1995; 61: 277-284

15 Cohen MZ, Easley MK, Ellis $C$ et al. Cancer pain management and the JCAHO's pain standards: an institutional challenge. J Pain Symptom Manage 2003; 25: 519-527

16 van Boeckel PG, Siersema PD, Sturgess $R$ et al. A new partially covered metal stent for palliation of malignant dysphagia: a prospective follow-up study. Gastrointest Endosc 2010; 72: 1269-1273

17 van Boeckel PG, Repici A, Vleggaar FP et al. A new metal stent with a controlled-release system for palliation of malignant dysphagia: a prospective, multicenter study. Gastrointest Endosc 2010; 71: 455-460

18 Choi SJ, Kim JH, Choi JW et al. Fully covered, retrievable self-expanding metal stents (Niti-S) in palliation of malignant dysphagia: long-term results of a prospective study. Scand J Gastroenterol 2011; 46: 875880

19 Van Heel NC, Haringsma J, Spaander MC et al. Esophageal stents for the palliation of malignant dysphagia and fistula recurrence after esophagectomy. Gastrointest Endosc 2010; 72: 249-254

20 Van Heel NC, Haringsma J, Spaander MC et al. Esophageal stents for the relief of malignant dysphagia due to extrinsic compression. Endoscopy 2010; 42: 536- 540

21 Uitdehaag MJ, Siersema PD, Spaander MC et al. A new fully covered stent with antimigration properties for the palliation of malignant dysphagia: a prospective cohort study. Gastrointest Endosc 2010; 71: 600-605

22 Siersema PD, Hop WC, van Blankenstein M et al. A comparison of 3 types of covered metal stents for the palliation of patients with dysphagia caused by esophagogastric carcinoma: a prospective, randomized study. Gastrointest Endosc 2001; 54: 145 - 153

23 Verschuur EM, Repici A, Kuipers EJ et al. New design esophageal stents for the palliation of dysphagia from esophageal or gastric cardia cancer: a randomized trial. Am J Gastroenterol 2008; 103: 304-312

24 Verschuur EM, Kuipers EJ, Siersema PD. Esophageal stents for malignant strictures close to the upper esophageal sphincter. Gastrointest Endosc 2007; 66: $1082-1090$

25 Homs MY, Hansen BE, van Blankenstein $M$ et al. Prior radiation and/or chemotherapy has no effect on the outcome of metal stent placement for oesophagogastric carcinoma. Eur J Gastroenterol Hepatol 2004; 16: $163-170$

26 Lecleire S, Di Fiore F, Ben-Soussan E et al. Prior chemoradiotherapy is associated with a higher life-threatening complication rate after palliative insertion of metal stents in patients with oesophageal cancer. Aliment Pharmacol Ther 2006; 23: 1693-1702

27 Verschuur EM, Steyerberg EW, Kuipers EJ et al. Effect of stent size on complications and recurrent dysphagia in patients with esophageal or gastric cardia cancer. Gastrointest Endosc 2007; 65: 592-601

28 Morrison LJ, Morrison RS. Palliative care and pain management. Med Clin North Am 2006; 90: 983-1004

29 Hirdes MM, Vleggaar FP, de Beule $M$ et al. In vitro evaluation of the radial and axial force of self-expanding esophageal stents. Endoscopy 2013; 45: 997-1005

30 Hirdes MM, Siersema PD, Vleggaar FP. A new fully covered metal stent for the treatment of benign and malignant dysphagia: a prospective follow-up study. Gastrointest Endosc 2012; 75: 712 - 718 